\title{
Parenchymal-sparing Hepatectomy as the New Doctrine in the Treatment of Liver-metastatic Colorectal Disease: Beyond Oncological Outcomes
}

\author{
DEMETRIOS MORIS ${ }^{1}$, DIMITRIOS DIMITROULIS ${ }^{2}$, SPIRIDON VERNADAKIS $^{3}$, \\ ALEXANDROS PAPALAMPROS ${ }^{4}$, ELEFTHERIOS SPARTALIS ${ }^{3}$, \\ ATHANASIOS PETROU ${ }^{4}$, TIMOTHY M. PAWLIK ${ }^{5}$ and EVANGELOS FELEKOURAS ${ }^{4}$ \\ ${ }^{1}$ Department of Immunology, Lerner Research Institute, Cleveland Clinic, Cleveland, OH, U.S.A.; \\ ${ }^{2}$ Second Department of Propedeutic Surgery, Laikon General Hospital, \\ National and Kapodistrian University of Athens, Athens, Greece; \\ ${ }^{3}$ Transplant Unit, Laikon General Hospital, Athens, Greece; \\ ${ }^{4}$ First Department of Surgery, Laikon General Hospital, \\ National and Kapodistrian University of Athens, Athens, Greece; \\ ${ }^{5}$ Department of Surgery, The Ohio State University Wexner Medical Center, Columbus, OH, U.S.A.
}

\begin{abstract}
Colorectal cancer is one of the leading causes of mortality in the Western world. Half of patients with colorectal cancer will develop liver-metastatic (CLM) disease, with fewer than $30 \%$ having surgically resectable disease at diagnosis. It is well established in the literature that major hepatectomy offers a high rate of $R 0$ resection, however, with concommitant increased rates of mortality and morbidity. Emerging literature during the past two decades has demonstrated the potential superiority of parenchymal-sparing hepatectomy $(P S H)$ in treating CLM disease in terms of oncological outcomes, survival and re-operation in cases of recurrence (salvageability). To date, no data regarding the evaluation of quality of life and cost after PSH have been published. PSH seems to be correlated with less mortality and morbidity, which can be translated in lower re-admission rates, better quality of life and, therefore, reduced relevant cost. Prospective studies and clinical trials evaluating the multiple
\end{abstract}

This article is freely accessible online.

Correspondence to: Demetrios Moris MD, Ph.D.. Department of Immunology, Lerner Research Institute, Cleveland Clinic, 9500 Euclid Ave., NE60, Cleveland, OH 44195, U.S.A. Tel: +1 2164442574, Fax: +1 2164454658, e-mail: dimmoris@yahoo.com

Key Words: Parenchymal-sparing hepatectomy, colorectal liver metastatic disease, anatomical hepatectomy, non-anatomical hepatectomy, review. beneficial role of a PSH surgical strategy in CLM disease are mandatory to support or reject the emerging belief that PSH could be the gold standard of treatment of CLM disease.

Colorectal carcinoma (CRC) is the third most frequent cancer in the world, with nearly 1.23 million new cases diagnosed each year $(1,2)$. About half of these patients will develop liver metastases during the course of their disease, causing two-thirds of deaths (1). Hepatectomy is considered the cornerstone of treatment for colorectal liver metastases (CLM), demonstrating a relatively high 5-year survival rate of up to $50 \%(2,3)$. There are more than 1,000 hepatic resections and ablations performed for CLM each year in the United States, with an overall complication rate of $40 \%$ (4). The extensive surgery that is often performed may be associated with short-term suffering from the surgery and related complications, permanent loss of function, readily visible deformity, high economic cost and even death. Previously, hepatectomy was only performed in selected patients who had a small number and size of nodules. However, advances in multidisciplinary treatment mean that hepatectomy can be offered to patients with advanced CLM $(2,5-7)$. This was the outcome of the enormous effort and persistence of hepatobiliary surgeons, pushing the frontiers of resectability in patients with malignant liver tumors.

This attitude gave birth to a new paradigm or doctrine focusing on "what remains after resection" rather than to "what is resected" (8). Surgeons performing oncological liver surgery must find the intricate balance between two 
conflicting objectives that might jeopardize each other whenever extensive disease is present. Firstly, there is the potential to achieve a complete tumor resection with curative intent-negative microscopic margins (R0 resection). Secondly, there is the potential to preserve as much liver parenchyma as possible to avoid liver failure. The need for preserving non-tumor parenchyma (salvageability), as well as the progressive expansion of resectability criteria for CLM, mainly related to the significant reduction of what was considered a sufficient tumor margin, has led to the development of a surgical concept known as parenchymalsparing hepatectomy (PSH). The aim of the present analysis was to discuss the pros and cons of PSH in the treatment of CLM as well as to highlight future directions in the field.

\section{The Outcomes of PSH: Achieving More with Less}

The philosophy behind PSH includes many surgical strategies aiming to offer minimum sufficient margins in order to preserve as much liver parenchyma as possible. This approach was thought to be correlated with increased rate of recurrence due to closer margins and a greater amount of at-risk future liver remnant in which metastases could seed. This turned out not to be the case. Data from the present analysis reflect a growing body of evidence that has accumulated over the past decade which have suggested that perhaps more can be achieved with less. For example, almost a decade ago, Pawlik et al. demonstrated that the width of a negative surgical margin after hepatectomy did not affect survival, recurrence risk or site of recurrence (9). In fact, Adam et al. have suggested that even a microscopically-positive R1 margin does not impact overall survival (7). PSH is an optimal procedure in this regard, offering less invasiveness with better short-term outcomes than major hepatectomy. More specifically, a recent study demonstrated that PSH for solitary CLM increased the chance of salvage resection for liver recurrence without increasing recurrence in the liver remnant $(10,11)$. In the same frame, another study demonstrated the striking finding that PSH did not negatively impact on overall, recurrence-free and liver-only recurrence-free survival and was a beneficial factor for candidacy for repeat hepatectomy, without increased risk of recurrence (10). Moreover, repeat resection in patients with recurrent disease after CLM resection has been shown to offer the potential for long-term disease control without increasing perioperative mortality and morbidity rates (12). In other words, surgery for recurrent CLM is feasible, with similar morbidity and mortality rates to those of initial or single CLM resections $(13,14)$. Moreover, PSH can be a reliable choice in the setting of bilateral CLM, with acceptable morbidity, mortality and oncological results (15). It was also recently shown that PSH seems to be appropriate for deep-placed CLM (>30 $\mathrm{mm}$ from the liver surface) since it was performed safely without compromising oncological radicality (16).
PSH seems to have a role in treatment of advanced CLMs that have a high risk of recurrence because the surgical margins are close to the tumors and residual parenchyma has a high risk of future liver metastases. A recent study in patients with advanced CLM found that PSH did not increase positive surgical margin or liver recurrence in comparison with major hepatectomy. Thus, a parenchymal-sparing approach offers a high rate of salvageability (11).

PSH can increase the number of patients eligible for an operation by halving the resection volume and by increasing the chance of direct operative treatment in patients with illlocated CLM (16). Moreover, with the application of techniques that induce future liver remnant hypertrophy and liver regeneration $(17,18)$, PSH might offer even superior results in terms of residual liver function. There is a clear trend toward PSH in hepatobiliary centers worldwide as current evidence indicates that tumor biology is the most important predictor of intrahepatic recurrence and survival, rather than the extent of a negative resection margin (19). Tumor removal avoiding the unnecessary sacrifice of functional parenchyma has been associated with less surgical stress, fewer postoperative complications, uncompromised cancer-related outcomes and higher feasibility of future resections. The increasing evidence supporting PSH has prompted its consideration as the gold-standard surgical approach for CLM (19) (Figure 1).

\section{Surgery for CLM and Quality of Life}

Another parameter that should also be highlighted is the disability that the surgical treatment of CRC can cause. The number of hepatic resections is increasing worldwide and procedures are becoming far more complex. Moreover, multimodality care such as chemotherapy, aggressive surgical resections and other treatments could offer survival benefit in patients with CLM or advanced CRC with a concomitant price to be paid, namely the deterioration of the quality of life and functionality (disability) (20).

Usually after major surgery for malignancy, many patients report a number of physical problems such as pain, physical inactivity or sexual dysfunction, despite their relatively good, general, subjective health and social and psychological wellbeing (20). Full recovery after CRC surgery allows a return to normal physical and psychological health and to a normal social life. To date, recovery data have focused on time to discharge rather than long-term functionality including return to work (21).

In Europe, one-quarter of patients diagnosed with CRC are under the age of 65 years, with the age for state pension eligibility having risen to 67 years; this will significantly increase the number of patients of working age diagnosed with CRC (22). For patients diagnosed with CRC whilst in employment, full recovery including return to work is vital 

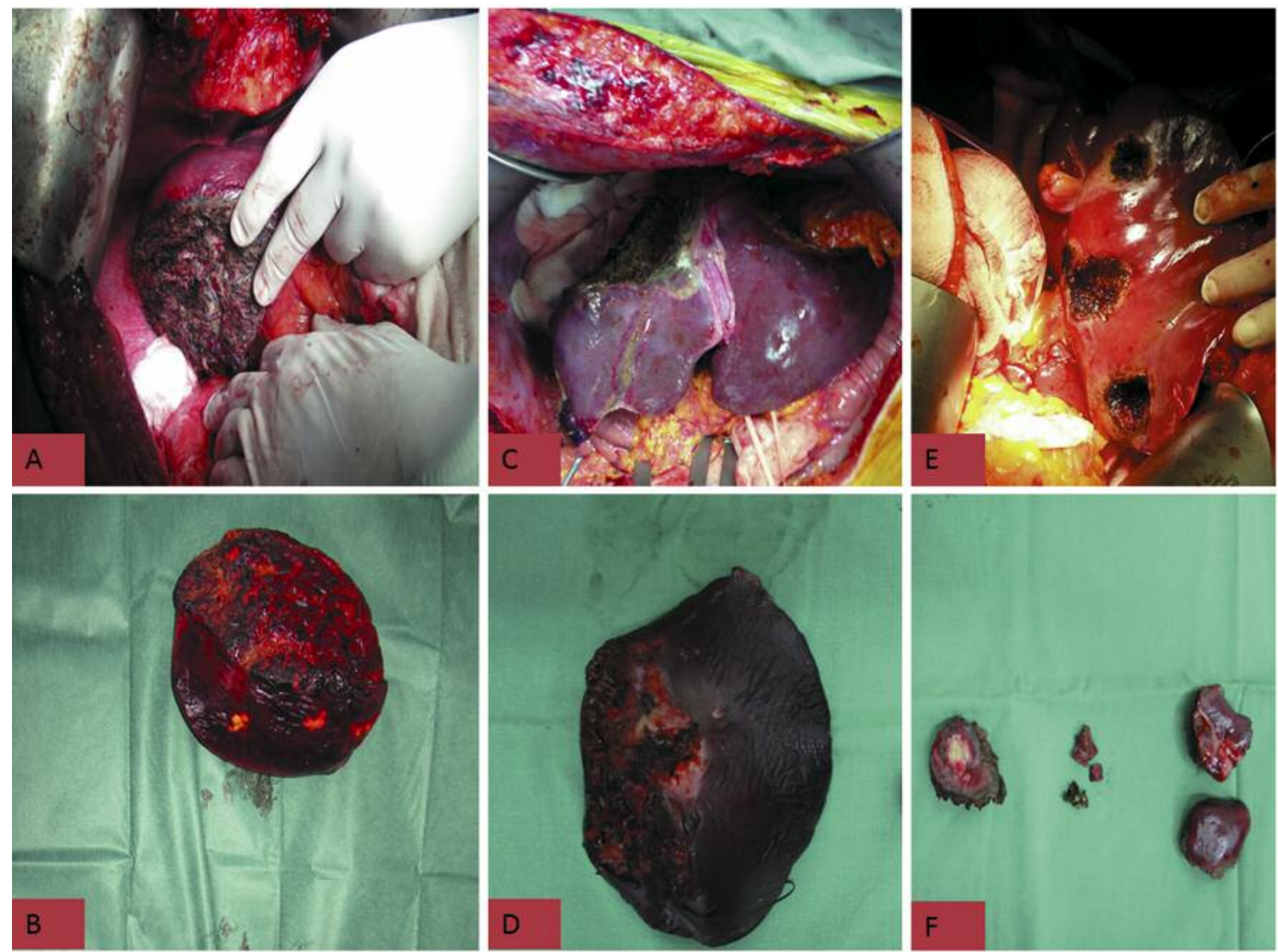

Figure 1. Images illustrating different types of liver resection for liver metastases from colorectal cancer. A: Anatomical right hepatectomy: B: Liver parenchyma resected after anatomical resection. C: Non-anatomical parenchymal-sparing hepatectomy. D: Liver parenchyma resected after nonanatomical resection. E: Wedge parenchymal-sparing hepatectomy. F: Liver parenchyma resected after wedge parenchymal-sparing hepatectomy.

in maintaining socio-economic status. A recent study demonstrated that the total number of disability-adjusted life years lost due to cancer in middle-aged and older adults was 382 per 1,000 individuals, with CRC being responsible for almost one-seventh of that loss (22). In the same vein, another study demonstrated that more than one-third of the employed patients with CRC were unable to return to work 1 year after surgery for CRC (23).

As for the treatment of CLM, it is also reasonable to state that major hepatectomies, like all major operations, are amputative procedures that can severely affect quality of life. It was demonstrated that patients undergoing major hepatectomy return to their baseline quality of life at 3 months after surgery, with a progressive and sustained increase in physical, emotional and global functionality at 6 months (24). Despite the fact that only 6 months are enough to restore quality of life after major hepatectomy, in the current era of a demanding daily life, 6 months is not a short period of time. Similarly, it was shown that patients undergoing major liver resections for malignancy demonstrate a sufficient long-term quality of life irrespective of their clinical prognosis (20). Moreover, overall quality of life in the first 3 years seems to be correlated with the initial successful surgical intervention and the potential for cure (25).

There is currently no clear evidence in the literature about the time required for returning to work after major or minor hepatectomy. Moreover, no study as far as we are aware has evaluated the effect of PSH in terms of quality of life and postoperative functionality. We suspect that PSH might cause less disability due to the reduced severity of the approach. We await for the prospective studies or trials evaluating disability rates after major hepatectomies or even PSH to be published.

\section{The Financial Burden of PSH}

Global financial instability and recession seem to severely affect national healthcare systems. Moreover, current healthcare reforms aim at controlling the escalating costs and improving the quality and delivery of health care (26). The 
relative impact of the recent global financial crisis on administrative, social and health structures is expected to vary greatly according to the individual economic capacity of each country and the availability of relevant resources. Countries of middle to low total income are at particular risk of undergoing a prolonged period of recession that will undoubtedly affect several aspects of public services (27-29).

Especially in the case of surgical care, the situation is more intense since it represents the most costly encounter within the healthcare system, with over $\$ 400$ billion spent annually on the care of surgical patients in the US (30). In terms of cost, the cost of minor hepatectomies has reached $\$ 46,600 /$ patient whereas major hepatectomy such as lobectomy or extended lobectomy is significantly more expensive ( $\$ 54,100$ and $\$ 60,100$, respectively) (31). Of interest, minor hepatectomy has been reported to be more expensive than major hepatectomy within 30 days of surgery due to early (30-day) re-admission. In contrast, the cost of late (90-day) re-admission after minor hepatectomy was less expensive than that after major hepatectomy cases (31). Moreover, major hepatectomies are correlated with increased risk of perioperative complications and consequent readmissions (32-34), which add significantly to the total cost of each operation and to the financial burden that social security services should cover. More specifically, substantial costs are incurred beyond the index surgical admission, with re-admissions representing a major source of potentially preventable healthcare spending (31). In light of these data, it is difficult to predict the ability of society to afford the burden of expenses associated with the increasing number of hepatectomies for CLM disease that will be performed in the years ahead.

Despite efforts at cost containment and healthcare reforms over the past several decades, the cost of surgical care in particular continues to rise (35). Important risk factors such as postoperative complications and re-admissions are modifiable costs that put a considerable burden on society and healthcare systems. As such, policymakers and healthcare professionals need to focus on identifying robust quality improvement initiatives that will result in cost reduction. Specifically, for complex procedures such as hepatectomy, proposals to reduce postoperative complications including referral to high-volume centers, implementation of Enhanced Recovery After Surgery (ERAS) pathways, and adoption of bundle payment plans are particularly relevant. For example, the per-patient cost of a hepatic resection at low-volume centers was recently reported to be $21.9 \%$ higher than at high-volume centers (35). Even at high-volume centers, ERAS strategies can drive down costs even further among patients undergoing hepatic resection(36). Future payment models are likely increasingly to be adopted that will bundle or cap reimbursement, limiting hospital payment, especially in the setting of a complicated postoperative course (37). The increased projected operative case numbers for CLM combined with ongoing soaring healthcare costs demands that surgeons and healthcare providers focus on improving quality, as well as managing expenses when treating patients with complex surgical diseases.

In this frame, it is highly difficult to predict the redundancy of the social security system in affording the burden of the expenses of the increasing number of hepatectomies that will be needed for the years to come for CLM disease $(38,39)$. Thus, we believe that PSH could offer a cost-effective therapeutic solution since it seems to be correlated with fewer postoperative complications compared with major liver resections.

\section{Conclusion}

There are emerging data supporting the potential superiority of PSH in treating CLM disease. PSH seems to be noninferior to the current standard-of-care of CLM in terms of oncological outcomes and survival. In the same frame, it offers 'friendlier' surgical conditions for re-operation in cases of recurrence (salvageability). The potential for reoperation could make CLM disease a chronic disease that is different from the current belief that CLM is an end-stage disease.

Moreover, PSH seems to be correlated with less mortality and morbidity rates that can be translated in lower readmission rates, better quality of life and reduced relevant cost. Thus, prospective studies and clinical trials on evaluating the multiple beneficial role of PSH surgical strategy in CLM disease are mandatory in order to support or reject the emerging belief that PSH could be the gold standard of treatment of CLM disease.

\section{Funding}

None.

\section{Conflicts of Interest}

All Authors declare that they have no competing interests in regard to this study.

\section{References}

1 Abdalla EK, Adam R, Bilchik AJ, Jaeck D, Vauthey JN and Mahvi D: Improving resectability of hepatic colorectal metastases: Expert consensus statement. Ann Surg Oncol 13(10): 1271-1280, 2006.

2 de Haas RJ, Wicherts DA, Andreani P, Pascal G, Saliba F, Ichai P, Adam R, Castaing D and Azoulay D: Impact of expanding criteria for resectability of colorectal metastases on short- and long-term outcomes after hepatic resection. Ann Surg 253(6): 1069-1079, 2011. 
3 Saiura A, Yamamoto J, Koga R, Takahashi Y, Takahashi M, Inoue Y, Ono Y and Kokudo N: Favorable outcome after repeat resection for colorectal liver metastases. Ann Surg Oncol 21(13): 4293-4299, 2014

4 Eid S, Stromberg AJ, Ames S, Ellis S, McMasters KM and Martin RC: Assessment of symptom experience in patients undergoing hepatic resection or ablation. Cancer 107(11): 27152722, 2006 .

5 Wicherts DA, Miller R, de Haas RJ, Bitsakou G, Vibert E, Veilhan LA, Azoulay D, Bismuth H, Castaing D and Adam R: Long-term results of two-stage hepatectomy for irresectable colorectal cancer liver metastases. Ann Surg 248(6): 994-1005, 2008.

6 Masi G, Cupini S, Marcucci L, Cerri E, Loupakis F, Allegrini G, Brunetti IM, Pfanner E, Viti M, Goletti O, Filipponi F and Falcone A: Treatment with 5-fluorouracil/folinic acid, oxaliplatin, and irinotecan enables surgical resection of metastases in patients with initially unresectable metastatic colorectal cancer. Ann Surg Oncol 13(1): 58-65, 2006.

7 Adam R, Delvart V, Pascal G, Valeanu A, Castaing D, Azoulay D, Giacchetti S, Paule B, Kunstlinger F, Ghemard O, Levi F and Bismuth H: Rescue surgery for unresectable colorectal liver metastases downstaged by chemotherapy: A model to predict long-term survival. Ann Surg 240(4): 644-657; discussion 657 $648,2004$.

8 Charnsangavej C, Clary B, Fong Y, Grothey A, Pawlik TM and Choti MA: Selection of patients for resection of hepatic colorectal metastases: Expert consensus statement. Ann Surg Oncol 13(10): 1261-1268, 2006.

9 Pawlik TM, Scoggins CR, Zorzi D, Abdalla EK, Andres A, Eng C, Curley SA, Loyer EM, Muratore A, Mentha G, Capussotti L and Vauthey JN: Effect of surgical margin status on survival and site of recurrence after hepatic resection for colorectal metastases. Ann Surg 241(5): 715-722, discussion 722-714, 2005.

10 Mise Y, Aloia TA, Brudvik KW, Schwarz L, Vauthey JN and Conrad C: Parenchymal-sparing hepatectomy in colorectal liver metastasis improves salvageability and survival. Ann Surg 263(1): 146-152, 2016.

11 Matsumura M, Mise Y, Saiura A, Inoue Y, Ishizawa T, Ichida H, Matsuki R, Tanaka M, Takeda Y and Takahashi Y: Parenchymalsparing hepatectomy does not increase intrahepatic recurrence in patients with advanced colorectal liver metastases. Ann Surg Oncol, 2016.

12 Oba M, Hasegawa K, Shindoh J, Yamashita S, Sakamoto Y, Makuuchi M and Kokudo N: Survival benefit of repeat resection of successive recurrences after the initial hepatic resection for colorectal liver metastases. Surgery 159(2): 632-640, 2016.

13 Wicherts DA, de Haas RJ, Salloum C, Andreani P, Pascal G, Sotirov D, Adam R, Castaing D and Azoulay D: Repeat hepatectomy for recurrent colorectal metastases. Br J Surg 100(6): 808-818, 2013

14 Kulik U, Bektas H, Klempnauer J and Lehner F: Repeat liver resection for colorectal metastases. Br J Surg 100(7): 926-932, 2013.

15 Gold JS, Are C, Kornprat P, Jarnagin WR, Gonen M, Fong Y, DeMatteo RP, Blumgart LH and D'Angelica M: Increased use of parenchymal-sparing surgery for bilateral liver metastases from colorectal cancer is associated with improved mortality without change in oncologic outcome: Trends in treatment over time in 440 patients. Ann Surg 247(1): 109-117, 2008.
16 Matsuki R, Mise Y, Saiura A, Inoue Y, Ishizawa T and Takahashi Y: Parenchymal-sparing hepatectomy for deep-placed colorectal liver metastases. Surgery, 2016.

17 Moris D, Dimitroulis D, Papalampros A, Petrou A and Felekouras E: Alpps procedure for hepatocellular carcinoma in patients with chronic liver disease: Revealing a terra incognita. Ann Surg, 2016.

18 Moris D, Vernadakis S, Papalampros A, Vailas M, Dimitrokallis N, Petrou A and Dimitroulis D: Mechanistic insights of rapid liver regeneration after associating liver partition and portal vein ligation for stage hepatectomy. World J Gastroenterol 22(33): 7613-7624, 2016.

19 Alvarez FA, Sanchez Claria R, Oggero S and de Santibanes E: Parenchymal-sparing liver surgery in patients with colorectal carcinoma liver metastases. World J Gastrointest Surg 8(6): 407423, 2016.

20 Banz VM, Inderbitzin D, Fankhauser R, Studer P and Candinas D: Long-term quality of life after hepatic resection: Health is not simply the absence of disease. World J Surg 33(7): 1473-1480, 2009.

21 Group EC: The impact of enhanced recovery protocol compliance on elective colorectal cancer resection: Results from an international registry. Ann Surg 261(6): 1153-1159, 2015.

22 Tsilidis KK, Papadimitriou N, Capothanassi D, Bamia C, Benetou V, Jenab M, Freisling H, Kee F, Nelen A, O'Doherty MG, Scott A, Soerjomataram I, Tjonneland A, May AM, Ramon Quiros J, Pettersson-Kymmer U, Brenner H, Schottker B, Ordonez-Mena JM, Karina Dieffenbach A, Eriksson S, Bogeberg Mathiesen E, Njolstad I, Siganos G, Wilsgaard T, Boffetta P, Trichopoulos D and Trichopoulou A: Burden of cancer in a large consortium of prospective cohorts in Europe. J Natl Cancer Inst 108(10), 2016.

23 Bhalla A, Williams JP, Hurst NG, Speake WJ, Tierney GM, Tou $\mathrm{S}$ and Lund JN: One-third of patients fail to return to work 1 year after surgery for colorectal cancer. Tech Coloproctol 18(12): 1153-1159, 2014.

24 Martin RC, Eid S, Scoggins CR and McMasters KM: Healthrelated quality of life: Return to baseline after major and minor liver resection. Surgery 142(5): 676-684, 2007.

25 Wiering B, Oyen WJ, Adang EM, van der Sijp JR, Roumen RM, de Jong KP, Ruers TJ and Krabbe PF: Long-term global quality of life in patients treated for colorectal liver metastases. Br J Surg 98(4): 565-571; discussion 571-562, 2011.

26 LaPar DJ, Bhamidipati CM, Mery CM, Stukenborg GJ, Jones DR, Schirmer BD, Kron IL and Ailawadi G: Primary payer status affects mortality for major surgical operations. Ann Surg 252(3): 544-550; discussion 550-541, 2010.

27 Karidis NP, Dimitroulis D and Kouraklis G: Global financial crisis and surgical practice: The Greek paradigm. World J Surg 35(11): 2377-2381, 2011.

28 Moris D, Zavos G, Menoudakou G, Karampinis A and Boletis $\mathrm{J}$ : Organ donation during the financial crisis in Greece. Lancet 387(10027): 1511-1512, 2016.

29 Moris D, Felekouras E and Linos D: Global surgery initiative in Greece: More than an essential initiative. Lancet 388(10048): 957, 2016.

30 Gani F, Hundt J, Daniel M, Efron JE, Makary MA and Pawlik TM: Variations in hospitals costs for surgical procedures: Inefficient care or sick patients? Am J Surg, 2016. 
31 Kulaylat AN, Schubart JR, Schaefer EW, Hollenbeak CS, Cooper AB and Gusani NJ: Costs of hepato-pancreato-biliary surgery and readmissions in privately insured us patients. J Surg Res 199(2): 478-486, 2015.

32 Tamandl D, Butte JM, Allen PJ, D'Angelica MI, DeMatteo RP, Groeger JS, Jarnagin WR and Fong Y: Hospital readmissions after liver surgery for metastatic colorectal cancer. Surgery 157(2): 231-238, 2015.

33 Kim Y, Gani F, Canner JK, Margonis GA, Makary MA, Schneider EB and Pawlik TM: Hospital readmission after multiple major operative procedures among patients with employer provided health insurance. Surgery 160(1): 178-190, 2016.

34 Spolverato G, Ejaz A, Kim Y, Weiss M, Wolfgang CL, Hirose K and Pawlik TM: Readmission incidence and associated factors after a hepatic resection at a major hepato-pancreatico-biliary academic centre. HPB 16(11): 972-978, 2014.

35 Sutton JM, Hoehn RS, Ertel AE, Wilson GC, Hanseman DJ, Wima K, Sussman JJ, Ahmad SA, Shah SA and Abbott DE: Cost-effectiveness in hepatic lobectomy: The effect of case volume on mortality, readmission, and cost of care. J Gastrointest Surg 20(2): 253-261, 2016.
36 Page AJ, Gani F, Crowley KT, Lee KH, Grant MC, Zavadsky TL, Hobson D, Wu C, Wick EC and Pawlik TM: Patient outcomes and provider perceptions following implementation of a standardized perioperative care pathway for open liver resection. Br J Surg 103(5): 564-571, 2016.

37 Gani F, Hundt J, Makary MA, Haider AH, Zogg CK and Pawlik TM: Financial impact of postoperative complication following hepato-pancreatico-biliary surgery for cancer. Ann Surg Oncol 23(4): 1064-1070, 2016.

38 Kim Y, Amini N, He J, Margonis GA, Weiss M, Wolfgang CL, Makary M, Hirose K, Spolverato G and Pawlik TM: National trends in the use of surgery for benign hepatic tumors in the united states. Surgery 157(6): 1055-1064, 2015.

39 Nathan H, Segev DL, Mayo SC, Choti MA, Cameron AM, Wolfgang CL, Hirose K, Edil BH, Schulick RD and Pawlik TM: National trends in surgical procedures for hepatocellular carcinoma: 1998-2008. Cancer 118(7): 1838-1844, 2012.

Received October 28, 2016

Revised November 14, 2016

Accepted November 15, 2016 